Психология. Журнал Высшей школы экономики,

2011. T. 8, № 1. С. 101-121.

\title{
ПСИХОФИЗИОЛОГИЧЕСКАЯ И ЛИНГВИСТИЧЕСКАЯ СОСТАВЛЯЮЩИЕ В ЦВЕТОВЫХ НАЗВАНИЯХ РУССКОГО ЯЗЫКА
}

\author{
Ю.А. ЧУДИНА, Ч.А. ИЗМАЙЛОВ
}

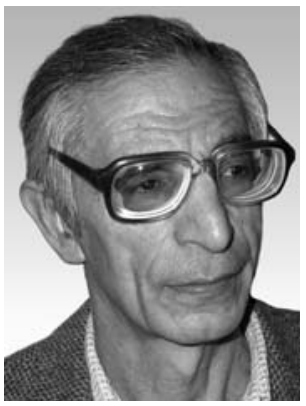

Измайлов Чингиз Абильфазович - профессор факультета психологии МГУ им. М.В. Ломоносова, доктор психологических наук. Область научных интересов - восприятие цвета и формы, психофизиология эмоций, психологические измерения, математическая психология, моделирование нейронных сетей зрения. Является автором книг: «Сферическая модель цветоразличения» (1980), «Психофизиология цветового зрения» (1989, в соавт.), «Психофизиологические основы эмоций» (2004, в соавт.).

Контакты: ch_izmailov@mail.ru

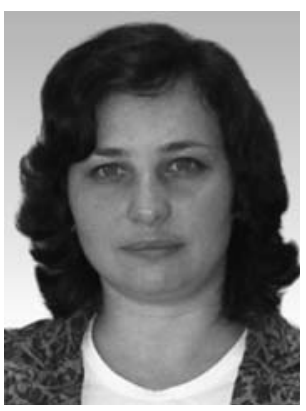

Чудина Юлия Александровна - доцент филологического факультета Российского университета дружбы народов, кандидат психологических наук. Область научных интересов - восприятие формы, цветовые названия, цветовое зрение.

\section{Резюме}

В работе рассмотрена проблема выделения названий непредметных (синий, зеленый и т.д.) и предметных иветов (лимонный, розовый и т.д.). Методом многомерного шкалирования иветовых названий построены семантические пространства: общее, пространство предметных и непредметных названий.

Непредметные цветовые названия образуют более устойчивую конфигурацию точек-стимулов по сравнению с конфигурацией предметных иветовых названий. Это позволяет связать формирование непредметных цветовых названий с психофизиологическим устройством иветового зрения, тогда как формирование предметных цветовых названий определяется речевым опытом.

Ключевые слова: предметные и непредметные иветовые названия, многомерное шкалирование, семантическое пространство иветоразличения, иветовое зрение, речевой опыт.

Работа поддержана грантами РГНФ № 10-06-00302а и РФФИ № 10-06-00438а. 


\section{Введение}

Нет другого феномена психики, который играет такую значительную роль в жизнедеятельности человека, как восприятие цвета. Быт, искусство, промышленность, наука, религия - все насыщенно цветовым содержанием. Показательно, что выяснение мозговых механизмов цветового зрения стало первым феноменом психики, на который было обращено внимание таких ученых, как И. Ньютон, Г. Гельмгольц, Дж. Максвелл, Э. Шредингер. Именно их работы лежат в основе современной цветовой науки (Wyszecki, Stiles, 1982; Измайлов, Соколов, Черноризов, 1989). Казалось бы, цветовое зрение, должно быть представлено соответствующим образом и в эволюции живых организмов. По крайней мере, так, как представлены мозговые механизмы интеллекта (Келер, 1930).

Однако это не так. У большинства представителей млекопитающих, которые являются наиболее высокоорганизованной ветвью дерева биологической эволюции, цветовое зрение имеет вырожденную форму. Большинство млекопитающих монохроматы или дихроматы, и только приматы обладают полноценным трихроматическим зрением, а многие представители более низкоразвитых ветвей эволюции (насекомые, земноводные, птицы, рыбы) имеют высокоразвитое цветовое зрение (Константинов, Соколов, Бызов, 1980; Смит, 2005; Супин, 1981).

Биология цветового зрения ясно показывает, что большая роль цвета в человеческой цивилизации не связана с необходимостью адаптации к внешней среде, как это характерно для обоснования развития некоторых других, простых (например, бинокулярное зрение) или сложных (например, интеллект) когнитивных функций. С другой стороны, с древнейших времен обнаружена тесная связь цвета с культурной (в широком смысле) жизнедеятельностью человека. Об этом свидетельствуют археологические и этнографические данные о ритуальной и военной раскраске древних или примитивных народов, а также мифология и фольклор разных народов мира. Роль цвета в жизнедеятельности человека также многократно отражена в художественной литературе, в живописи и музыке (Гете, 1957; Карева, 2005; Кандинский, 1918; Яньшин, 2006). Но наиболее общим отражением роли цвета в жизнедеятельности человека является речь, в частности, слова - названия цветов. Поэтому естественно, что исследованию структуры цветовых названий большое внимание уделяется в лингвистике и психолингвистике.

Исследование цветовых названий в лингвистике выявило одну очень важную особенность, которая состоит в разделении всех цветовых названий на две группы. Исследования Б. Берлина и К. Кея (Berlin, Кау, 1969) структуры цветовых названий в разных языках показали, что существует несколько цветовых названий (так называемых универсалий), которые присутствуют во всех языках, тогда как остальные цветовые названия разные языки включают в свой словарь в разных вариантах. Первая группа названий совпадает с базисными цветами, выделяемыми по разным основаниям в исследованиях 
цветового зрения, а другая - из предметных (Katz, 1935; Джадд, Вышецкий, 1978). Разные авторы дискутируют по поводу числа базисных цветов (от трех до одиннадцати), но все согласны, что в эту группу входят названия основных цветов спектра (фиолетовый, синий, зеленый, желтый, красный), белый и черный цвета. В русском языке к ним добавляются «голубой» и «оранжевый». Обсуждается возможность включения в этот список «коричневого». К предметным названиям цвета относят слова, имеющие общие корни с названиями некоторых предметов с ярко выраженной цветовой характеристикой. Например, слова «золотой», «лимонный», «апельсиновый» однокоренные со словами «золото», «лимон», «апельсин», которые обозначают предметы с характерными цветовыми свойствами. Любой из этих предметов может иметь цветовые характеристики в очень широкой гамме цветов от зеленого до красного, но, тем не менее, они употребляются для обозначения оттенков желтого цвета. В соответствии с такой привязкой названий к типичной окраске предметов в работе для обозначения этих цветов будет использоваться термин «предметные цветовые названия», а для обозначения базисных цветов «непредметные цветовые названия».

Эта дихотомия в какой-то степени напоминает дихотомию цветов поверхности и апертурных цветов (Джадд, Вышецкий, 1978; Нюберг, 1928; Федоров, 1935; Katz, 1935). В отличие от апертурных цветов, которые связаны с прямой стимуляцией сетчатки световым излучением, цвет поверхности связан со стимуля- цией отраженным от предмета светом. Поэтому цвет поверхности иногда называют предметным цветом, но эта аналогия не имеет оснований, поскольку в ряде работ показано, что кодирование цвета в зрительной системе не зависит от этой дихотомии стимуляции, механизм цветового зрения у человека в обоих случаях стимуляции один и тот же (Джадд, Вышецкий, 1978; Измайлов, 2010). В отличие от апертурного цвета и цвета поверхности предметным может называться только цвет реального объекта, который имеет форму, текстуру и фигуро-фоновые отношения. В этом случае кодирование цвета определяется не столько спектральными характеристиками светового излучения от поверхности этого объекта, сколько кодированием пространственно-временных характеристик паттерна излучения (Измайлов, 2010; Измайлов, Павлова, Ханмагомедова, 2009; Grossberg, 1984; Рок, 1980). В кодировании цвета объекта задействован не только механизм цветового зрения, но и другие сенсорные механизмы, которые все вместе формируют перцептивный механизм зрительной системы Нужно отметить, что многие исследователи прямо связывают перцепцию или восприятие с высшими когнитивными механизмами памяти, научения, интеллекта (Бонгард, 1967; Грегори, 1972; Шехтер, 1967). Определение предметного цвета как цвета реального объекта сближает это понятие с предметным цветовым названием в лингвистике, которое происходит от названия реального объекта и этимологически связано с ним. В то же время можно предположить, что базисные, непредметные названия 
цветов связаны с восприятием апертурных цветов и цветов поверхности, т.е. имеют сенсорное происхождение. Разделение цветов на непредметные (апертурные и цвета поверхности) и предметные (цвет реальных объектов) и их кодирование в зрительной системе сенсорными и перцептивными механизмами перекликается с дискуссией в лингвистике о биологической и культурной составляющих в природе цветовых названий (Вежбицкая, 1996).

Все исследователи согласны с тем, что два этих аспекта - культурный и биологический - взаимосвязаны, расхождение начинается в установлении соотношения этих двух составляющих. Например, П. Кей и Б. Берлин (Berlin, Kay, 1969) говорят о приоритете биологического аспекта, тогда как А. Вежбицкая (Вежбицкая, 1996) настаивает на культурном приоритете цветовых названий, относя к биологической составляющей названия, связанные не с цветовой, а со световой характеристикой слова, например, такие обозначения, как светлый и темный, тусклый и яркий, но не белый и черный.

В данной работе это соотношение исследуется в рамках психофизиологического подхода к зрительному восприятию, когда названия цвета используются как сложные зрительные стимулы, различение которых осуществляет специальная нейронная сеть. Этот подход предусматривает три основные характеристики экспериментального исследования: 1) оценки больших, надпороговых различий между стимулами; 2) построение геометрической модели различения стимулов в евклидовом пространстве методом многомерного шкалирования; 3) построение сферической модели стимулов, в которой сферические координаты пространства представляют субъективные (психологические) характеристики воспринимаемых стимулов, а декартовые координаты - нейрофизиологические каналы зрительной системы, которые образуют нейронную сеть восприятия данных стимулов (Sokolov, Izmailov, 1983; Соколов, Измайлов, 2006). Мы предположили, что все оценки цветовых названий, которые обоснованы биологически механизмом цветового зрения (непредметные названия), будут меньше варьировать от испытуемого к испытуемому по сравнению с оценками названий предметных цветов, поскольку биологический механизм цветового зрения у всех людей (трихроматов) не зависит от культурного влияния, тогда как названия предметных цветов ассоциируются у разных людей с объектами, характеризующимися значительно большим цветовым разнообразием. Эта разница будет выявлена при сопоставлении геометрических моделей различения соответствующих стимулов (предметных и непредметных названий цвета).

\section{Методика}

В опытах использовали 30 стимулов - цветовых названий русского языка. Десять из этих стимулов - названия непредметных цветов, а двадцать - из диапазона предметных цветов (таблица 1).

На экране монитора испытуемому предъявляли пару стимулов-слов, белыми буквами на темном фоне. Он оценивал цветовое различие между 
Таблица 1

Матрица оценок цветовых различий между стимулами - цветовыми названиями русского языка. Каждая оценка получена как среднее по 18 предъявлениям каждой пары стимулов

\begin{tabular}{|c|c|c|c|c|c|c|c|c|c|c|c|c|c|c|}
\hline & $\mathbf{2}$ & $\mathbf{3}$ & $\mathbf{4}$ & $\mathbf{5}$ & $\mathbf{6}$ & $\mathbf{7}$ & $\mathbf{8}$ & $\mathbf{9}$ & $\mathbf{1 0}$ & $\mathbf{1 1}$ & $\mathbf{1 2}$ & $\mathbf{1 3}$ & $\mathbf{1 4}$ & $\mathbf{1 5}$ \\
\hline $\mathbf{1}$ & 7.2 & 4.1 & 8.7 & 8.6 & 8.7 & 5.6 & 4.2 & 7.9 & 7.5 & 2.4 & 4.0 & 7.6 & 8.1 & 3.9 \\
\hline $\mathbf{2}$ & & 3.9 & 7.5 & 7.5 & 7.7 & 8.4 & 8.1 & 5.8 & 8.9 & 7.3 & 8.3 & 2.6 & 3.7 & 4.6 \\
\hline $\mathbf{3}$ & & & 7.9 & 7.9 & 8.4 & 7.6 & 7.4 & 7.5 & 8.6 & 5.8 & 7.1 & 4.9 & 4.1 & 4.0 \\
\hline $\mathbf{4}$ & & & & 7.2 & 7.5 & 8.2 & 7.9 & 7.2 & 8.3 & 8.4 & 8.2 & 6.2 & 7.2 & 8.3 \\
\hline $\mathbf{5}$ & & & & & 2.9 & 4.3 & 6.7 & 7.7 & 6.7 & 8.5 & 7.1 & 8.4 & 8.5 & 8.1 \\
\hline $\mathbf{6}$ & & & & & & 6.4 & 6.7 & 6.5 & 8.4 & 8.4 & 8.6 & 7.7 & 8.4 & 8.6 \\
\hline $\mathbf{7}$ & & & & & & & 5.3 & 7.8 & 5.9 & 5.8 & 5.3 & 8.4 & 7.9 & 8.1 \\
\hline $\mathbf{8}$ & & & & & & & & 8.2 & 7.8 & 4.6 & 5.6 & 8.1 & 8.2 & 7.1 \\
\hline $\mathbf{9}$ & & & & & & & & & 8.9 & 7.8 & 8.0 & 6.2 & 6.7 & 8.3 \\
\hline $\mathbf{1 0}$ & & & & & & & & & & 8.3 & 7.6 & 8.8 & 8.8 & 8.6 \\
\hline $\mathbf{1 1}$ & & & & & & & & & & & 5.1 & 7.6 & 7.2 & 6.0 \\
\hline $\mathbf{1 2}$ & & & & & & & & & & & & 8.2 & 8.3 & 5.6 \\
\hline $\mathbf{1 3}$ & & & & & & & & & & & & & 4.6 & 5.0 \\
\hline $\mathbf{1 4}$ & & & & & & & & & & & & & & 5.6 \\
\hline
\end{tabular}

Обозначения цветов:

$\begin{array}{ll}1-\text { красный } & 17-\text { салатовый } \\ 2-\text { желтый } & 18-\text { оливковый } \\ 3-\text { оранжевый } & 19-\text { аквамарин } \\ 4-\text { зеленый } & 20-\text { сливовый } \\ 5-\text { синий } & 21-\text { васильковый } \\ 6-\text { голубой } & 22-\text { бирюзовый } \\ 7-\text { фиолетовый } & 23-\text { баклажановый } \\ 8-\text { пурпурный } & 24-\text { свекольный } \\ 9-\text { белый } & 25-\text { малиновый } \\ 10-\text { черный } & 26-\text { розовый } \\ 11-\text { алый } & 27-\text { серебристый } \\ 12-\text { бордовый } & 28-\text { пепельный } \\ 13-\text { лимонный } & 29-\text { чернильный } \\ 14-\text { золотой } & 30-\text { угольный } \\ 15-\text { рыжий } & \\ 16-\text { апельсиновый } & \end{array}$


Таблииа 1 (продолжение)

\begin{tabular}{|c|c|c|c|c|c|c|c|c|c|c|c|c|c|c|c|}
\hline & 16 & 17 & 18 & 19 & 20 & 21 & 22 & 23 & 24 & 25 & 26 & 27 & 28 & 29 & 30 \\
\hline 1 & 6.1 & 8.2 & 7.7 & 7.8 & 6.3 & 7.6 & 8.3 & 5.3 & 4.6 & 3.0 & 3.8 & 8.6 & 8.1 & 8.2 & 8.1 \\
\hline 2 & 4.6 & 6.7 & 5.5 & 8.3 & 7.6 & 8.1 & 8.2 & 7.9 & 7.6 & 8.2 & 7.7 & 8.2 & 8.2 & 8.3 & 8.5 \\
\hline 3 & 4.1 & 7.5 & 6.2 & 7.6 & 7.8 & 7.8 & 8.1 & 7.9 & 7.6 & 6.8 & 7.6 & 8.0 & 8.4 & 8.0 & 8.8 \\
\hline 4 & 7.7 & 4.1 & 4.3 & 7.2 & 7.9 & 7.4 & 7.2 & 7.3 & 8.1 & 8.3 & 8.3 & 8.6 & 8.6 & 8.5 & 8.2 \\
\hline 5 & 8.8 & 7.5 & 7.7 & 4.9 & 4.8 & 4.3 & 6.0 & 5.9 & 6.2 & 7.7 & 8.3 & 8.1 & 7.4 & 5.7 & 7.3 \\
\hline 6 & 8.5 & 7.2 & 7.9 & 4.1 & 6.0 & 2.3 & 4.5 & 7.1 & 8.2 & 8.2 & 8.4 & 6.9 & 7.5 & 7.4 & 8.2 \\
\hline 7 & 8.4 & 8.2 & 7.7 & 6.9 & 4.2 & 4.9 & 6.6 & 3.5 & 3.7 & 4.6 & 5.7 & 8.5 & 7.9 & 5.7 & 7.2 \\
\hline 8 & 7.6 & 8.0 & 7.8 & 7.3 & 6.8 & 6.8 & 7.6 & 6.4 & 6.4 & 5.8 & 6.1 & 8.6 & 8.1 & 7.1 & 8.2 \\
\hline 9 & 7.8 & 7.5 & 7.4 & 7.2 & 7.3 & 7.2 & 6.9 & 7.5 & 8.2 & 7.6 & 7.0 & 4.6 & 6.0 & 8.4 & 8.4 \\
\hline 10 & 8.4 & 8.7 & 7.8 & 7.9 & 6.8 & 8.3 & 8.3 & 6.5 & 6.9 & 8.0 & 8.6 & 7.7 & 5.3 & 1.9 & 3.8 \\
\hline 11 & 6.2 & 8.6 & 7.5 & 6.4 & 6.2 & 7.6 & 7.5 & 6.3 & 5.3 & 3.7 & 3.9 & 8.3 & 7.8 & 8.2 & 8.3 \\
\hline 12 & 7.2 & 8.1 & 8.5 & 7.9 & 5.8 & 7.1 & 8.3 & 4.4 & 4.2 & 5.8 & 6.1 & 8.2 & 8.1 & 6.8 & 7.5 \\
\hline 13 & 3.2 & 5.6 & 5.7 & 7.3 & 7.5 & 7.8 & 7.8 & 8.3 & 7.9 & 7.8 & 8.2 & 7.7 & 7.8 & 8.8 & 8.2 \\
\hline 14 & 5.3 & 7.4 & 7.0 & 8.6 & 7.7 & 8.2 & 8.5 & 8.2 & 8.2 & 7.8 & 7.8 & 7.7 & 8.2 & 8.9 & 8.6 \\
\hline 15 & 4.2 & 8.1 & 7.8 & 8.1 & 7.6 & 8.5 & 8.2 & 8.1 & 7.4 & 7.7 & 7.8 & 7.9 & 8.6 & 8.1 & 8.0 \\
\hline 16 & & 7.8 & 6.9 & 7.7 & 7.8 & 7.9 & 8.3 & 8.0 & 7.4 & 6.4 & 6.8 & 7.8 & 8.4 & 8.6 & 8.5 \\
\hline 17 & & & 5.6 & 7.6 & 8.1 & 7.9 & 6.7 & 8.4 & 8.1 & 8.4 & 8.2 & 8.1 & 8.5 & 8.6 & 8.9 \\
\hline 18 & & & & 7.6 & 8.0 & 7.6 & 7.7 & 7.1 & 7.6 & 7.9 & 8.2 & 7.8 & 8.3 & 7.4 & 8.1 \\
\hline 19 & & & & & 6.7 & 5.4 & 6.8 & 6.6 & 8.3 & 7.9 & 6.9 & 6.7 & 7.9 & 7.9 & 8.3 \\
\hline 20 & & & & & & 6.3 & 7.4 & 4.7 & 5.8 & 6.1 & 6.1 & 8.1 & 8.5 & 6.1 & 7.7 \\
\hline 21 & & & & & & & 6.0 & 6.8 & 7.1 & 7.5 & 7.9 & 8.1 & 7.5 & 7.7 & 7.8 \\
\hline 22 & & & & & & & & 7.7 & 8.1 & 7.8 & 8.2 & 7.7 & 7.8 & 8.4 & 8.6 \\
\hline 23 & & & & & & & & & 6.6 & 6.5 & 6.1 & 7.9 & 8.4 & 5.7 & 7.3 \\
\hline 24 & & & & & & & & & & 5.6 & 5.2 & 8.4 & 8.0 & 5.8 & 7.5 \\
\hline 25 & & & & & & & & & & & 3.3 & 7.9 & 8.3 & 8.0 & 8.6 \\
\hline 26 & & & & & & & & & & & & 7.8 & 7.9 & 8.6 & 8.0 \\
\hline 27 & & & & & & & & & & & & & 4.7 & 7.3 & 6.6 \\
\hline 28 & & & & & & & & & & & & & & 5.9 & 6.1 \\
\hline 29 & & & & & & & & & & & & & & & 3.5 \\
\hline 30 & & & & & & & & & & & & & & & \\
\hline
\end{tabular}


стимулами-словами целым числом от одного (минимальное различие) до девяти (максимальное различие), независимо от того, состояла пара стимулов из предметных или комбинации предметных и непредметных названий цвета. Каждую пару предъявляли два раза для сохранения пространственной симметрии. Порядок стимулов в паре и последовательность предъявлений были псевдослучайными. Производить оценку испытуемый должен был как можно быстрее, не задумываясь и ориентируясь на первое впечатление. С этой целью длительность предъявления стимулов и время для ответа ограничивались двумя и одной секундами соответственно.

Испьтуемые. В опытах участвовали трихроматы (пять женщин и четверо мужчин в возрасте 21-27 лет), цветовое зрение у которых проверяли на анамалоскопе Раутиана AH-59.

\section{Результаты}

Оценки всех пар усредняли по предъявлениям и сводили для каждого испытуемого в матрицу попарных различий. Проверка матриц на коррелированность по Пирсону показала коэффициент линейной корреляции не менее 0.60 . Поэтому все матрицы усреднили также и по 9 испытуемым (таблица 1). Кроме общей матрицы различий между 30 стимулами, для анализа было взято еще две подматрицы: для 10 непредметных названий цвета и для 20 предметных названий. Поскольку все предъявления производились в случайном порядке, эти подматрицы можно рассматривать как резуль- таты независимых экспериментов по различению соответствующих стимулов. Все три группы данных обработали одним и тем же метрическим методом многомерного шкалирования (Shepard, 1964; Kruskal, 1964; Шепард, 1981). В результате анализа для каждой группы данных были получены координаты точек-стимулов в многомерном пространстве и показатели, по которым определялась значимость каждой из осей полученного пространства.

Рассмотрим, прежде всего, насколько согласуются полученные семантические пространства со сферической моделью цветоразличения. Основной характеристикой сферической модели является спецификация цвета как точки на сферической поверхности в четырехмерном евклидовом пространстве (Измайлов, 1981; Измайлов и др., 1989; Izmailov, Sokolov, 1991). В этом случае четыре декартовы координаты цветовой точки на сфере рассматриваются как четыре нейрофизиологических канала (два хроматических и два ахроматических), образующих нейронную сеть цветового зрения. В то же время три сферические координаты цветовой точки рассматриваются как субъективные характеристики цвета - цветовой тон, насыщенность и светлота. Между такими субъективными характеристиками, как цветовой тон и светлота, в нейронной сети цветового зрения устанавливается связь, которая задается соотношением между двумя парами декартовых координат (хроматическая $\mathrm{X}_{1} \mathrm{X}_{2}$ и ахроматическая $\mathrm{X}_{3} \mathrm{X}_{4}$ плоскости) и сферической координатой на этой плоскости (соответственно $\varphi_{1}$, и $\varphi_{2}$ ). Поскольку цветовой тон и светлота 
независимо связаны со своей парой нейрофизиологических каналов (такая пара каналов с соответствующей сферической структурой называется двухканальным модулем зрительной системы - Измайлов и др., 1989, 2006, 2008), они рассматриваются в сферической модели в качестве базисных характеристик цвета, тогда как цветовая насыщенность $\varphi_{3}$ рассматривается как производная характеристика, появившаяся в результате объединения хроматического и ахроматического модулей в четырехканальную сеть (Izmailov, Sokolov, 2004).

Таким образом, построение пространства, полученного из матрицы различий между словами-названиями цветов, основывали на выполнении двух условий: линейности между исходными оценками различий и межточечными евклидовыми расстояниями (Shepard, Carroll, 1966; Измайлов, 1981) в четырехмерном евклидовом пространстве и сферической структуры поверхности, на которой располагаются точки-стимулы в пространстве данной размерности (Измайлов, 1981; Измайлов, Соколов, Черноризов, 1989; Izmailov, Sokolov, 1991). Решение по первому условию оценивали «стрессом» Крускала, а по второму условию - коэффициентом вариации, который вычисляли как отношение стандартного отклонения радиус-векторов точек к среднему радиусу (Измайлов, Соколов, 1978; Измайлов, 1980).

Полученные значения показателей пространственного решения (стресс и коэффициент вариации) для стимулов - названий цветов для общего пространства цветовых на- званий, пространства непредметных и предметных цветовых названий свидетельствуют о том, что по этим значениям евклидово пространство только при четырехмерном решении достигает значения не более $10 \%$, которое отвечает условию сферической модели цветоразличения. Приведенные в таблице 2 показатели характеризуют только формальные аспекты полученного решения. Более важные - содержательные аспекты, т.е. соответствие конфигурации точек-стимулов в пространстве цветовым характеристикам названий, можно оценить только по расположению стимулов относительно системы координат (декартовой и сферической).

\section{Обсуждение результатов}

В соответствии со сферической моделью цветового зрения рассмотрим, прежде всего, проекцию точек, представляющих общее множество цветовых названий, на две плоскости полученного пространства $-\mathrm{X}_{1} \mathrm{X}_{2}$ и $\mathrm{X}_{3} \mathrm{X}_{4}$ (рисунок $1 \mathrm{~A}$, Б). Плоскость $\mathrm{X}_{1} \mathrm{X}_{2}$ представляет хроматические характеристики полученного пространства. На рисунке $1 \mathrm{~A}$ видно, что полученная конфигурация всех точек-стимулов согласуется с определением декартовых координат как двух цветооппонентных каналов зрительной системы, а сферическая координата этих же точек (горизонтальный угол точки на плоскости) соответствует основной субъективной характеристике цвета цветовому тону. Особенно хорошо это видно по расположению непредметных цветовых названий, которые обозначены на рисунке 1 только 
Значения стресса и коэффициента вариации радиуса сферы для данных по цветоразличению разных групा цветовых названий

\begin{tabular}{|l|c|c|c|c|c|c|c|c|c|c|}
\hline & \multicolumn{2}{|c|}{ ОП } & \multicolumn{2}{c|}{ БН } & \multicolumn{2}{c|}{ ПН } & \multicolumn{2}{|c|}{ 1-я группа } & \multicolumn{2}{c|}{ 2-я группа } \\
\hline & Стресс & Вариат. & Стресс & Вариат. & Стресс & Вариат. & Стресс & Вариат. & Стресс & Вариат. \\
\hline $\mathbf{1}$ & 0.407 & & 0.302 & & & & 0.402 & & 0.437 & \\
\hline $\mathbf{2}$ & 0.238 & 0.273 & 0.146 & & 0.261 & 0,289 & 0.245 & 0.313 & 0.257 & 0.224 \\
\hline $\mathbf{3}$ & 0.108 & 0.125 & 0.058 & 0.122 & 0.140 & 0.115 & 0.158 & 0.135 & 0.178 & 0.110 \\
\hline $\mathbf{4}$ & 0.091 & 0.088 & 0.038 & 0.098 & 0.100 & 0.085 & 0.122 & 0.099 & 0.132 & 0.086 \\
\hline $\mathbf{5}$ & 0.074 & 0.075 & 0.002 & 0.071 & 0.085 & 0.070 & 0.102 & 0.085 & 0.110 & 0.077 \\
\hline
\end{tabular}

Примечание. В первой графе показана размерность евклидова пространства, в следующих графах - данные для общего пространства цветовых названий (ОП), пространства беспредметных (БН) и предметных (ПН) цветовых названий, а также пространства цветовых названий для первой (1-я группа) и второй (2-я группа) подгрупп испытуемых.

первыми буквами. Однако в полученном пространстве есть некоторые особенности, отличающие его от сферической модели цветового зрения. Дело в том, что цветовая траектория точек-стимулов на плоскости $\mathrm{X}_{1} \mathrm{X}_{2}$ определяется не только цветовым тоном, но и насыщенностью цвета, которая представлена второй сферической координатой цветового пространства $\left(\varphi_{2}\right)$. На хроматической плоскости $\mathrm{X}_{1} \mathrm{X}_{2}$ насыщенность цвета представлена радиальным расстоянием точки от центра, который представляет чистый белый цвет. В связи с тем, что насыщенность спектрального желтого цвета значительно меньше, чем спектральных синего, зеленого и красного цветов, в пространстве цветовых стимулов траектория основных цветов спектра образует на хроматической плоскости форму треугольника с вершинами красного, зеленого и синего цветовых тонов. В нашем случае траектория основных цветовых названий на плоскости $\mathrm{X}_{1} \mathrm{X}_{2}$ образует не треугольник, а правильный ромб. Это означает, что цветовая насыщенность в названии цвета представлена не количественно, а только качественно, как отличие от белого. Такой вывод подтверждается положением остальных (предметных) названий цвета на плоскости $\mathrm{X}_{1} \mathrm{X}_{2}$. Эти цветовые названия еще больше выявляют ромбовидную конфигурацию точек-стимулов на рисунке 1А. Небольшие отклонения от идеальной ромбовидной траектории можно объяснить шумом экспериментальных данных, который представлен вариативностью радиусов в таблице 2 . Аналогичные выводы можно сделать и по конфигурации точек - цветовых названий на ахроматической плоскости цветового пространства $\mathrm{X}_{3} \mathrm{X}_{4}$ (рисунок 1Б). Названия ахроматических цветов от белого до черного располагаются в соответствии со сферической координатой $\varphi_{3}$ точки - горизонтальный угол на 


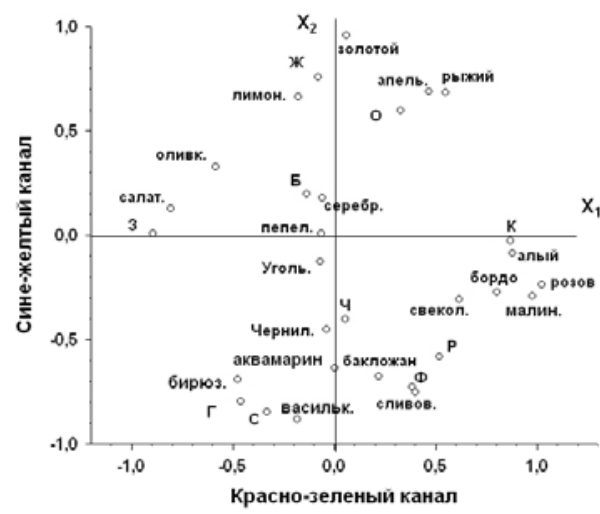

Рисунок 1 В

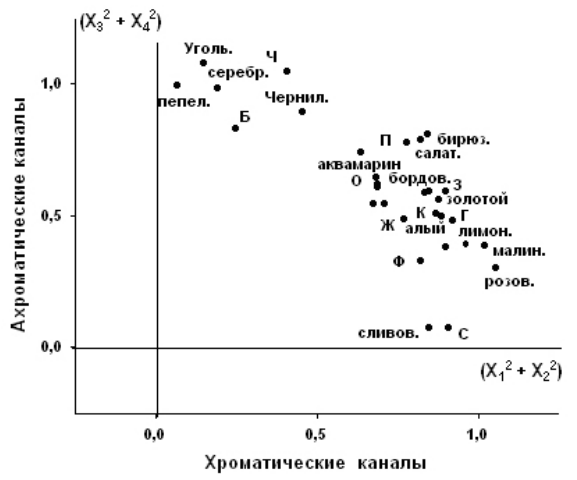

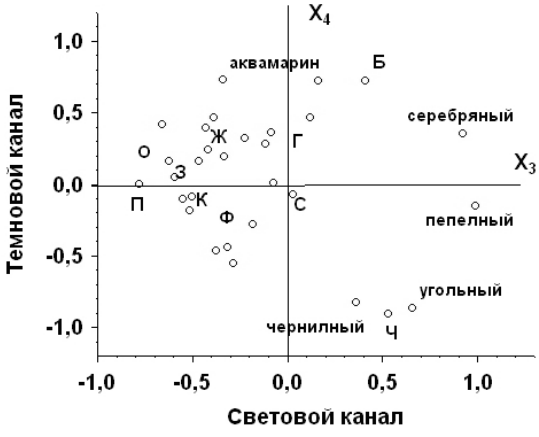

Примечание. Рисунок 1А. Расположение 30 цветовых стимулов-названий на хроматической плоскости $\mathrm{X}_{1} \mathrm{X}_{2}$ четырехмерного цветового пространства. Непредметные названия обозначены только первыми буквами. В отличие от конфигурации апертурных и предметных цветов, имеющих на хроматической плоскости треугольную форму с вершинами, в которых расположены базисные цвета С, 3 и К, конфигурация точек-названий имеет форму ромба с вершинами, в которых расположены базисные цвета C, 3, Ж и К. Рисунок 1Б. Расположение 30 цветовых стимулов-названий на ахроматической плоскости $\mathrm{X}_{3} \mathrm{X}_{4}$ четырехмерного цветового пространства. Рисунок 1В. Расположение 30 цветовых стимулов-названий на плоскости насыщенности, образованной хроматической $\left(\mathrm{X}_{1} \mathrm{X}_{2}\right)$ и ахроматической $\left(\mathrm{X}_{3} \mathrm{X}_{4}\right)$ плоскостями четырехмерного цветового пространства. Насыщенность апертурных и пигментных цветов характеризуется величиной угла радиус-вектора точки от белого цвета (минимальная насыщенность) до красного цвета (максимальная насыщенность). Видно, что все названия располагаются на этой плоскости в двух непересекающимихся областях - ахроматические и хроматические названия. Внутри области хроматических названий точки располагаются случайно, а не в соответствии с насыщенностью. Данные для 9 испытуемых.

плоскости $\mathrm{X}_{3} \mathrm{X}_{4}$, тогда как хроматические названия сгруппировались в противоположной половине плоскости в общий неупорядоченный клас- тер, что существенно отличает полученные данные от аналогичных данных для апертурных цветов (Izmailov, Sokolov, 1991) или цветов 
поверхности (Измайлов, 2010). Особенно наглядно это показывает расположение 30 цветовых стимулов-названий на плоскости насыщенности, образованной хроматической $\left(\mathrm{X}_{1} \mathrm{X}_{2}\right)$ и ахроматической $\left(\mathrm{X}_{3} \mathrm{X}_{4}\right)$ плоскостями четырехмерного цветового пространства (рисунок 1B). В соответствии с экспериментальными данными по измерению цветовой насыщенности (Martin, Yarburton, Morgen, 1933; Измайлов, 1981), насыщенность апертурных и пигментных цветов монотонно меняется от белого цвета (минимальная насыщенность) до основных цветов в следующем порядке: желтый, синий, зеленый и красный (максимальная насыщенность). В сферической модели цветоразличения насыщенность характеризуется величиной угла радиус-вектора точки на плоскости насыщенности (Измайлов, Соколов, Черноризов, 1989; Izmailov, Sokolov, 1991). Однако на рисунке 1B видно, что все ахроматические и хроматические названия располагаются на этой плоскости в двумх непересекающихся областях. Внутри области хроматических названий точки располагаются случайно, а не в соответствии с насыщенностью основных цветов. Полученные данные позволяют сделать вывод, что цветовые названия не варьируют по насыщенности, т.е. характеризуются только одной хроматической переменной цветовым тоном. Эти данные согласуются с результатами многомерного шкалирования искусственных цветовых названий (Izmailov, Sokolov, 1992), которые образуют на хроматической плоскости траекторию с одинаковой удаленностью всех цветовых точек от центра плоскости.
Полученное разделение слов-названий цветов по насыщенности на два класса (хроматические и ахроматические) позволяет предположить, что, возможно, цветовые названия образуют группы не только по насыщенности, но и по цветовому тону. Однако такое разделение маскируется большим числом групп, упорядоченных по цветовому тону. Для того чтобы прояснить эту ситуацию, мы рассмотрим раздельно пространство предметных и непредметных цветовых названий, полученных из соответствующих подматриц таблицы 1. На рисунке 2 показаны проекции точек - цветовых названий на хроматическую плоскость четырехмерного цветового пространства для непредметных (рисунок 2А) и предметных (рисунок 2Б) названий. Здесь результаты раздельного шкалирования подматриц непредметных и предметных названий (показаны кружками) сравниваются с результатами, полученными при анализе общей матрицы (показаны точками). Каждая пара сравниваемых названий на рисунке 2 связана отрезком, длина которого характеризует степень рассогласования между двумя вариантами анализа данных - общей матрицы различий и отдельно подматриц предметных и непредметных названий. Конечно, эту меру рассогласования нельзя рассматривать как абсолютную величину, а только как показатель тенденции. Сравнение графиков на рисунке 2 А и 2 Б показывает, что положение непредметных названий практически сохраняется при переходе от общей матрицы данных к отдельной подматрице, тогда как положение предметных названий в пространстве при таком переходе 

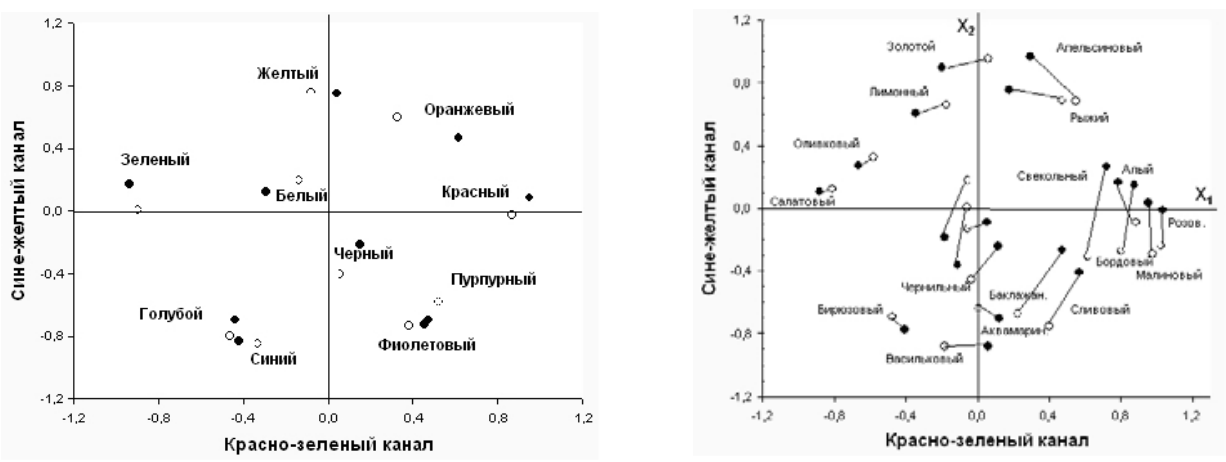

Примечание. Расположение 10 стимулов-названий непредметных цветов (А) и 20 стимулов-названий предметных цветов (Б) на хроматической плоскости $\mathrm{X}_{1} \mathrm{X}_{2}$, четырехмерного цветового пространства, полученных в результате раздельного анализа соответствующих подматриц, в сравнении с положением этих же цветовых названий по данным, полученным для общей матрицы (таблица 1). Кружками на обоих графиках обозначены данные подматриц непредметных $(10 \times 10)$ и предметных $(20 \times 20)$ названий, а точками - данные, полученные по общей матрице $(30 \times 30)$ цветовых названий. Данные для 9 испытуемых.

значительно меняется. Это означает, что названия непредметных цветов более независимы от контекста, чем предметных. Поскольку контекстом здесь являются индивидуальные различия (опыт использования цветовых названий и т.д.), которые мы объединяем под общим термином «культурные различия», это означает, что непредметные цветовые названия в большей степени связаны с устройством цветового зрения человека, чем предметные, которые больше связаны с культурным опытом.

Полученные данные - группировку предметных названий цвета по насыщенности и их зависимость от контекста - можно отнести на счет индивидуальных особенностей цветовой семантики, предполагая, что испытуемые (по аналогии с разными типами цветового зрения - дихроматами и трихроматами) на самом деле «видят» разные цвета, ассоциированные с одним и тем же названием, и это вносит систематическую ошибку в данные, которая не устраняется за счет усреднения, а, наоборот, с увеличением числа испытуемых только увеличивает общий шум. В этом случае уменьшение числа испытуемых должно привести к улучшению как формальных, так и содержательных характеристик пространства цветовых названий. Это предположение об индивидуальной специфичности цветовой семантики можно проверить, если аналогичный анализ провести для меньших групп испытуемых, сравнивая их между собой и с полученным выше решением (таблица 1 и рисунок $2 \mathrm{~A}$, Б).

С этой целью были выделены две подгруппы испытуемых (по четыре человека в каждой подгруппе), и оценки цветовых различий между 
названиями цветов, усредненные по 8 предъявлениям отдельно по каждой подгруппе, были сведены в две матрицы различий (таблица 3 ), которые анализировались точно так же, как общая матрица различий для девяти испытуемых. Полученные данные приведены в таблице 4 и на рисунке 3 А, Б.

Из таблицы 4 видно, что уменьшение числа испытуемых в группе нисколько не улучшило сферическую модель цветовых названий, коэффициент вариации практически не изменился в одной подгруппе (7.7\%) и даже несколько ухудшился в другой подгруппе (9.9\%). Кроме того, для обеих подгрупп значительно ухудшился стресс - показатель соответствия межточечных расстояний в четырехмерном пространстве и исходных оценок межстимульных различий. Полученный результат объясняется уменьшением количества оценок каждой пары стимулов (8 в подгруппе из 4 испытуемых и 18 в общей матрице), использованных путем усреднения, а это значит, что уменьшение числа испытуемых только увеличивает случайный шум и не вносит никаких изменений, связанных с систематической ошибкой, которая была бы вызвана индивидуальной спецификой цветовых обозначений у разных испытуемых.

Аналогичный вывод следует из сравнения конфигураций точек цветовых названий в цветовом семантическом пространстве, полученном путем усреднения ответов 9 испытуемых, с аналогичными данными двух подгрупп по 4 испытуемых в каждой. Для непредметных цветовых названий (рисунок 3А) данные практически не изменились по срав- нению с графиками на рисунке 2А. Каждая группа из трех точек, представляющих одно и то же название цвета на рисунке 3А, связана двумя прямыми линиями, соединяющими общие данные (точки) с данными для подгрупп испытуемых (кружки и треугольники). Длина этих линий показывает, что разброс точек внутри триады не увеличился. В то же время для предметных цветовых названий (рисунок 3Б) данные не только не улучшились, а, наоборот, разброс внутри каждой триады точек увеличился по сравнению с данными на рисунке 2Б. Это особенно хорошо видно на примере точек, соответствующих следующим цветовым названиям: желтый, зеленый и голубой.

Таким образом, мы можем заключить, что выделение из цветовых названий особой группы непредметных цветов обосновано психофизиологически через прямую связь с двумя основными нейрофизиологическими модулями системы цветового зрения, кодирующими цветовой тон и ахроматическую составляющую, которая определяет не только светлоту, но и бело-черную характеристику цвета (Измайлов, 1981; Измайлов, Соколов, Черноризов, 1989; Heggelund, 1992). Отсутствие вклада насыщенности в цветовые названия также объясняется специфическим устройством нейронной сети цветового зрения, в которой насыщенность формируется не за счет специфического двухканального модуля, как цветовой тон или светлота, а как результат объединения двух двухканальных модулей в четырехканальную сеть (Измайлов, Соколов, Едренкин, 2008; Izmailov, Sokolov, 2004). 
Две треугольные матрицы оценок цветовых различий между стимулами - цветовыми названиями русского языка, представляющие две группы по 4 испытуемых в каждой. Каждая оценка получена как среднее по 8 предъявлениям пары стимулов.

(Обозначения цветов см. в таблице 1)

\begin{tabular}{|c|c|c|c|c|c|c|c|c|c|c|c|c|c|c|c|}
\hline & 1 & 2 & 3 & 4 & 5 & 6 & 7 & 8 & 9 & 10 & 11 & 12 & 13 & 14 & 15 \\
\hline 1 & 0.0 & 6.8 & 3.5 & 8.4 & 8.4 & 8.6 & 5.8 & 2.4 & 8.5 & 8.8 & 1.9 & 3.6 & 7.4 & 7.1 & 4.8 \\
\hline 2 & 7.1 & 0.0 & 4.1 & 7.0 & 8.3 & 8.6 & 8.0 & 7.5 & 6.9 & 8.8 & 7.0 & 8.6 & 2.8 & 2.6 & 5.8 \\
\hline 3 & 4.5 & 3.4 & 0.0 & 7.8 & 8.4 & 8.1 & 8.0 & 7.4 & 7.0 & 8.9 & 5.4 & 6.5 & 5.4 & 3.4 & 4.1 \\
\hline 4 & 9.0 & 7.6 & 7.8 & 0.0 & 7.1 & 7.1 & 7.9 & 7.8 & 7.8 & 8.4 & 8.4 & 8.1 & 6.5 & 7.0 & 8.1 \\
\hline 5 & 8.6 & 7.4 & 8.1 & 7.9 & 0.0 & 2.8 & 6.0 & 6.1 & 8.8 & 7.0 & 8.8 & 7.5 & 8.4 & 8.5 & 8.0 \\
\hline 6 & 8.6 & 6.5 & 8.6 & 7.5 & 3.5 & 0.0 & 7.3 & 7.4 & 6.9 & 8.3 & 8.1 & 8.6 & 8.3 & 8.0 & 8.4 \\
\hline 7 & 6.5 & 8.6 & 6.9 & 8.4 & 3.5 & 4.9 & 0.0 & 4.0 & 8.1 & 7.8 & 5.1 & 6.1 & 8.6 & 7.5 & 7.8 \\
\hline 8 & 4.9 & 8.4 & 7.0 & 7.8 & 7.6 & 7.4 & 5.8 & 0.0 & 7.8 & 8.8 & 2.9 & 6.4 & 8.5 & 8.0 & 7.0 \\
\hline 9 & 7.1 & 3.9 & 7.6 & 6.3 & 6.4 & 5.5 & 7.3 & 8.5 & 0.0 & 8.9 & 7.5 & 7.6 & 7.3 & 8.1 & 8.3 \\
\hline 10 & 6.9 & 9.0 & 8.3 & 8.1 & 5.8 & 8.4 & 3.4 & 6.6 & 9.0 & 0.0 & 8.9 & 7.6 & 8.5 & 8.5 & 8.9 \\
\hline 11 & 3.3 & 7.3 & 6.4 & 8.3 & 8.1 & 8.6 & 5.6 & 6.3 & 7.8 & 7.6 & 0.0 & 4.5 & 6.1 & 6.1 & 5.4 \\
\hline 12 & 4.1 & 7.8 & 8.3 & 8.1 & 6.1 & 8.4 & 5.5 & 4.9 & 8.1 & 7.3 & 4.8 & 0.0 & 8.3 & 8.0 & 6.6 \\
\hline 13 & 7.5 & 2.9 & 5.5 & 5.3 & 8.4 & 6.8 & 8.0 & 7.4 & 4.5 & 9.0 & 8.8 & 7.9 & 0.0 & 4.6 & 4.4 \\
\hline 14 & 8.8 & 4.5 & 5.6 & 7.0 & 8.4 & 8.8 & 8.0 & 8.1 & 5.8 & 9.0 & 7.8 & 8.4 & 4.4 & 0.0 & 5.3 \\
\hline 15 & 3.8 & 4.3 & 2.6 & 8.4 & 7.9 & 8.8 & 8.3 & 6.6 & 8.3 & 8.3 & 5.9 & 5.8 & 5.6 & 6.0 & 0.0 \\
\hline 16 & 6.8 & 3.6 & 4.9 & 6.9 & 8.9 & 8.6 & 8.9 & 8.3 & 6.8 & 8.6 & 7.9 & 7.8 & 4.3 & 5.3 & 3.3 \\
\hline 17 & 8.3 & 6.4 & 7.1 & 4.4 & 7.1 & 6.6 & 8.3 & 7.9 & 6.8 & 8.6 & 8.9 & 8.6 & 3.8 & 6.9 & 7.9 \\
\hline 18 & 8.3 & 5.1 & 6.1 & 3.5 & 7.5 & 7.8 & 7.5 & 7.9 & 7.1 & 6.9 & 8.5 & 8.6 & 5.6 & 6.9 & 7.9 \\
\hline 19 & 8.1 & 8.1 & 6.9 & 8.0 & 6.6 & 5.0 & 7.3 & 7.8 & 6.1 & 7.3 & 6.8 & 8.5 & 7.0 & 8.6 & 7.8 \\
\hline 20 & 6.1 & 7.8 & 7.9 & 8.0 & 4.5 & 6.5 & 4.3 & 6.9 & 7.1 & 6.0 & 7.0 & 5.5 & 7.0 & 7.4 & 8.3 \\
\hline 21 & 7.8 & 7.9 & 8.3 & 7.0 & 4.8 & 2.1 & 5.1 & 6.6 & 6.3 & 8.1 & 7.1 & 6.9 & 7.0 & 8.0 & 8.8 \\
\hline 22 & 8.4 & 8.3 & 7.6 & 8.5 & 5.4 & 3.3 & 7.4 & 8.4 & 5.9 & 8.3 & 7.3 & 7.8 & 7.8 & 8.6 & 8.4 \\
\hline 23 & 6.0 & 7.5 & 7.4 & 7.0 & 4.8 & 7.8 & 3.8 & 6.0 & 7.8 & 5.1 & 6.1 & 4.4 & 8.5 & 8.1 & 8.3 \\
\hline 24 & 4.4 & 7.5 & 8.0 & 8.0 & 6.5 & 8.5 & 4.0 & 5 & 8.4 & 6.1 & 7.1 & 3.9 & 7.8 & 7.9 & 7.3 \\
\hline 25 & 3.9 & 8.8 & 6.5 & 8.3 & 8.4 & 7.9 & 5.4 & 6.4 & 6.9 & 8.0 & 4.3 & 7.5 & 8.3 & 7.6 & 8.0 \\
\hline 26 & 4.8 & 7.5 & 7.3 & 8.1 & 8.3 & 8.1 & 5.8 & 6.6 & 5.9 & 8.0 & 3.5 & 6.4 & 8.1 & 8.6 & 8.0 \\
\hline 27 & 8.8 & 8.5 & 8.4 & 8.8 & 8.1 & 5.9 & 8.6 & 8.8 & 4.9 & 7.5 & 8.8 & 8.3 & 8.1 & 7.8 & 8.6 \\
\hline 28 & 7.6 & 8.6 & 8.3 & 8.8 & 7.1 & 7.3 & 7.1 & 7.8 & 6.5 & 3.6 & 7.9 & 8.0 & 8.0 & 8.8 & 8.6 \\
\hline 29 & 7.8 & 8.4 & 7.8 & 8.3 & 3.9 & 6.5 & 3.3 & 5.9 & 8.8 & 2.8 & 7.4 & 5.1 & 8.8 & 8.8 & 7.6 \\
\hline 30 & 7.4 & 7.9 & 8.6 & 7.4 & 6.9 & 8.0 & 6.8 & 7.9 & 8.5 & 2.3 & 7.9 & 6.5 & 7.6 & 8.4 & 7.0 \\
\hline
\end{tabular}


Таблица 3 (продолжение)

\begin{tabular}{|c|c|c|c|c|c|c|c|c|c|c|c|c|c|c|c|}
\hline & 16 & 17 & 18 & 19 & 20 & 21 & 22 & 23 & 24 & 25 & 26 & 27 & 28 & 29 & 30 \\
\hline 1 & 5.6 & 8.0 & 6.9 & 7.1 & 5.9 & 7.1 & 8.1 & 4.8 & 4.8 & 2.6 & 3.6 & 8.4 & 8.3 & 8.5 & 8.6 \\
\hline 2 & 5.5 & 6.5 & 5.0 & 8.3 & 8.0 & 8.0 & 8.0 & 8.0 & 7.3 & 7.5 & 7.5 & 7.6 & 7.5 & 8.1 & 9.0 \\
\hline 3 & 4.0 & 7.5 & 6.6 & 7.9 & 7.5 & 8.0 & 8.3 & 8.3 & 6.8 & 6.5 & 7.5 & 7.4 & 8.5 & 8.0 & 9.0 \\
\hline 4 & 8.3 & 4.6 & 4.0 & 6.0 & 7.6 & 7.4 & 5.4 & 7.1 & 7.9 & 8.1 & 8.3 & 8.3 & 8.3 & 8.6 & 8.8 \\
\hline 5 & 8.6 & 7.5 & 7.5 & 4.3 & 4.0 & 3.6 & 6.9 & 6.3 & 5.3 & 6.6 & 8.1 & 7.8 & 7.3 & 6.8 & 7.3 \\
\hline 6 & 8.3 & 7.3 & 7.8 & 3.0 & 5.8 & 2.9 & 5.6 & 6.0 & 7.6 & 8.4 & 8.6 & 7.5 & 7.4 & 8.0 & 8.3 \\
\hline 7 & 7.8 & 7.9 & 7.6 & 6.1 & 2.9 & 3.8 & 7.1 & 2.9 & 3.1 & 4.8 & 4.8 & 8.3 & 8.4 & 7.3 & 7.1 \\
\hline 8 & 6.6 & 7.9 & 7.5 & 6.5 & 6.1 & 6.5 & 7.5 & 6.3 & 6.8 & 5.5 & 4.8 & 8.4 & 8.3 & 7.9 & 8.4 \\
\hline 9 & 8.6 & 7.9 & 7.4 & 7.8 & 7.1 & 7.6 & 7.4 & 6.9 & 7.8 & 8.0 & 7.6 & 4.1 & 4.8 & 8.0 & 8.1 \\
\hline 10 & 8.1 & 8.6 & 8.5 & 8.4 & 7.0 & 8.4 & 8.3 & 7.3 & 7.3 & 8.8 & 9.0 & 7.5 & 6.0 & 1.4 & 5.1 \\
\hline 11 & 5.8 & 8.3 & 6.1 & 5.5 & 4.6 & 7.8 & 8.4 & 5.8 & 3.5 & 2.9 & 4.1 & 7.6 & 7.5 & 8.8 & 8.6 \\
\hline 12 & 6.3 & 7.4 & 8.3 & 7.0 & 5.3 & 6.9 & 8.6 & 4.4 & 4.4 & 4.4 & 6.1 & 8.0 & 8.0 & 7.9 & 8.1 \\
\hline 13 & 2.8 & 6.5 & 6.0 & 7.3 & 7.6 & 8.3 & 7.6 & 7.9 & 7.9 & 7.1 & 8.0 & 7.0 & 7.4 & 8.8 & 8.5 \\
\hline 14 & 4.5 & 7.5 & 6.6 & 8.4 & 7.6 & 8.3 & 8.3 & 8.1 & 8.4 & 7.8 & 6.8 & 8.3 & 7.4 & 9.0 & 8.8 \\
\hline 15 & 4.9 & 8.0 & 7.4 & 8.1 & 6.5 & 8.1 & 7.9 & 7.8 & 7.3 & 7.0 & 7.4 & 7.9 & 8.4 & 8.3 & 8.8 \\
\hline 16 & 0.0 & 7.3 & 6.0 & 7.8 & 7.6 & 8.5 & 7.9 & 7.3 & 6.3 & 6.1 & 6.1 & 7.9 & 8.6 & 8.9 & 8.8 \\
\hline 17 & 8.0 & 0.0 & 6.1 & 7.5 & 7.8 & 7.5 & 6.9 & 8.5 & 7.9 & 8.3 & 8.5 & 8.3 & 8.6 & 8.6 & 8.9 \\
\hline 18 & 7.4 & 4.1 & 0.0 & 7.6 & 8.0 & 7.4 & 7.0 & 6.0 & 7.5 & 7.9 & 7.8 & 8.4 & 8.4 & 7.1 & 8.4 \\
\hline 19 & 7.4 & 7.4 & 7.3 & 0.0 & 6.0 & 5.9 & 6.6 & 5.8 & 8.0 & 8.1 & 6.5 & 6.0 & 7.3 & 8.3 & 8.8 \\
\hline 20 & 7.8 & 8.1 & 7.8 & 6.8 & 0.0 & 5.0 & 6.6 & 3.9 & 4.1 & 5.0 & 4.6 & 7.6 & 8.6 & 6.9 & 7.9 \\
\hline 21 & 7.1 & 8.0 & 7.4 & 4.1 & 7.0 & 0.0 & 6.5 & 6.1 & 6.3 & 6.9 & 7.1 & 8.3 & 6.8 & 8.0 & 6.9 \\
\hline 22 & 8.6 & 6.0 & 8.0 & 6.5 & 7.9 & 4.8 & 0.0 & 7.9 & 7.9 & 8.1 & 8.4 & 7.4 & 7.5 & 8.9 & 8.5 \\
\hline 23 & 8.5 & 8.1 & 7.6 & 6.8 & 4.5 & 6.9 & 7.1 & 0.0 & 6.9 & 5.3 & 6.4 & 8.1 & 8.3 & 6.0 & 7.3 \\
\hline 24 & 8.1 & 8.1 & 7.3 & 8.5 & 6.6 & 7.5 & 8.1 & 5.8 & 0.0 & 4.9 & 4.4 & 8.3 & 8.0 & 6.9 & 7.5 \\
\hline 25 & 6.0 & 8.4 & 7.6 & 7.5 & 6.4 & 7.8 & 7.3 & 7.1 & 5.5 & 0.0 & 3.9 & 8.1 & 7.9 & 7.9 & 8.6 \\
\hline 26 & 6.9 & 7.8 & 8.5 & 7.8 & 6.9 & 8.5 & 7.9 & 5.0 & 5.1 & 3.3 & 0.0 & 8.4 & 7.1 & 8.6 & 8.3 \\
\hline 27 & 7.5 & 7.6 & 8.0 & 6.8 & 8.4 & 7.8 & 7.8 & 8.5 & 8.4 & 7.4 & 7.9 & 0.0 & 4.4 & 7.5 & 6.6 \\
\hline 28 & 8.1 & 8.3 & 8.1 & 8.4 & 8.3 & 7.9 & 7.8 & 8.4 & 7.8 & 8.6 & 8.4 & 5.0 & 0.0 & 5.3 & 6.1 \\
\hline 29 & 8.1 & 8.5 & 7.3 & 7.3 & 4.5 & 7.0 & 7.9 & 4.5 & 3.9 & 7.9 & 8.5 & 6.8 & 5.8 & 0.0 & 4.3 \\
\hline 30 & 8.1 & 8.9 & 7.6 & 7.8 & 7.1 & 8.5 & 8.5 & 6.9 & 7.1 & 8.5 & 7.5 & 6.0 & 6.3 & 2.4 & 0.0 \\
\hline
\end{tabular}



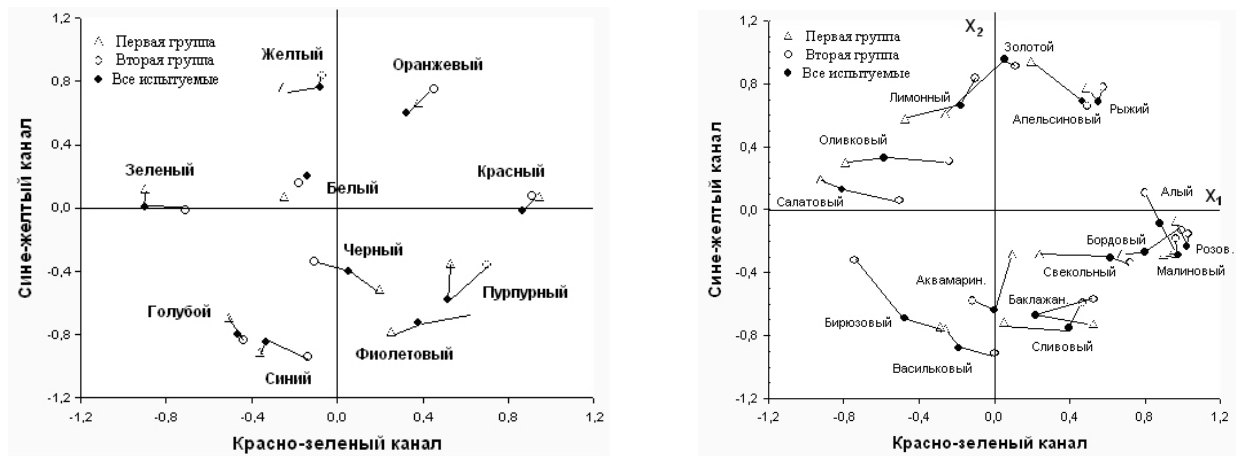

Примечание. Расположение 10 стимулов-названий непредметных цветов (А) и 20 стимулов-названий предметных цветов (Б) на хроматической плоскости $\mathrm{X}_{1} \mathrm{X}_{2}$ четырехмерного цветового пространства. Данные для первой и второй групп испытуемых приведены в сравнении с данными, полученными при усреднении по всем испытуемым (таблица 1).

Значения стресса и коэффициента вариации радиуса сферы для данных по цветоразличению разных групп цветовых названий

\begin{tabular}{|c|c|c|c|c|c|c|}
\hline & \multicolumn{2}{|c|}{ ОП } & \multicolumn{2}{c|}{ 1-я группа } & \multicolumn{2}{c|}{ 2-я группа } \\
\hline & Стресс & Вариат. & Стресс & Вариат. & Стресс & Вариат. \\
\hline $\mathbf{1}$ & 0.407 & & 0.402 & & 0.437 & \\
\hline $\mathbf{2}$ & 0.238 & 27.3 & 0.245 & 31.3 & 0.257 & 22.4 \\
\hline $\mathbf{3}$ & 0.108 & 12.5 & 0.158 & 13.5 & 0.178 & 11.0 \\
\hline $\mathbf{4}$ & 0.091 & 8.8 & 0.122 & 9.9 & 0.132 & 8.6 \\
\hline $\mathbf{5}$ & 0.074 & 7.5 & 0.102 & 8.5 & 0.110 & 7.7 \\
\hline
\end{tabular}

Примечание. В первой графе показана размерность евклидова пространства, в следующих графах - данные для общего пространства цветовых названий (ОП) и для пространства цветовых названий первой (1-я группа) и второй подгрупп (2-я группа) испытуемых. 
На рисунке 4 приводится возможная схема участия психофизиологического механизма цветового зрения и речевой системы в формирование цветовых названий. Можно предположить, что в области V1 зрительной коры, где обрабатывается информация от двухканальных модулей, в частности от хроматического и ахроматического модулей цветового зрения, происходит ее перераспределение по двум направлениям: в область V2, где хроматический и ахроматический модули объединяются и формируют трехмерную (цветовой тон, насыщенность, светлота) карту цветовых детекторов, и в область V4, где хроматический и ахроматический модули независимо включаются в формирование полимодальных нейронных сетей с конфигурационными модулями, такими как модуль ориентации или текстуры. Эти нейронные сети детектируют предметные цвета, в которых характеристика насыщенности цвета редуцируется.

Далее информация от полимодальных сетей передается в инферотемпоральную кору, где формируются карты детекторов, представляющих уже сложные предметные образы. Если такая схема верна, то при формировании цветовых названий речевые зоны мозга вначале получают цветовую информацию в основном от нейронных сетей области V4, и как результат - непредметные цветовые названия (характеризующиеся в основном цветовым тоном), а по мере развития связей инферотемпоральной коры с речевыми зонами мозга формируется система предметных цветовых названий. При формировании непредмет- ных цветовых названий раздельное влияние двухканальных модулей цветового тона и светлоты приводит к появлению названий, характерных для каждого модуля в отдельности, (например, светлый, темный, белый, черный для ахроматического модуля и красный, синий, зеленый, желтый для хроматического модуля (Bimler et al., 2009)). В этом смысле мнение А. Вежбицкой (Вежбицкая, 1996) о приоритете яркостных названий обосновано тем, что ахроматический модуль в это время более активен, чем хроматический, что, в частности, отражается в цветовом зрении доминированием яркости над цветовым тоном (эффект Бецольда-Брюкке).

С другой стороны, нейронные сети инферотемпоральной коры более пластичны, чем сети области V4, они более чувствительны к влиянию речевых областей мозга и, соответственно, больше впитывают в себя разнообразный речевой опыт. Это объясняет доминирование психолингвистической составляющей в предметных цветовых названиях.

Отдельный вопрос для обсуждения касается списка непредметных цветовых названий, использованных в нашей работе. Шесть хроматических (фиолетовый, синий, голубой, зеленый, желтый и красный) и два ахроматических (белый и черный) цветовых названия русского языка не вызывают возражений, тогда как «оранжевый» и «пурпурный» имеют в русском языке явное предметное происхождение. Однако в соответствии с нашим критерием разделения предметных и непредметных названий данные, приведенные на рисунках $2 \mathrm{~A}$ и $3 \mathrm{~A}$, показывают, что они в семантическом пространстве также 


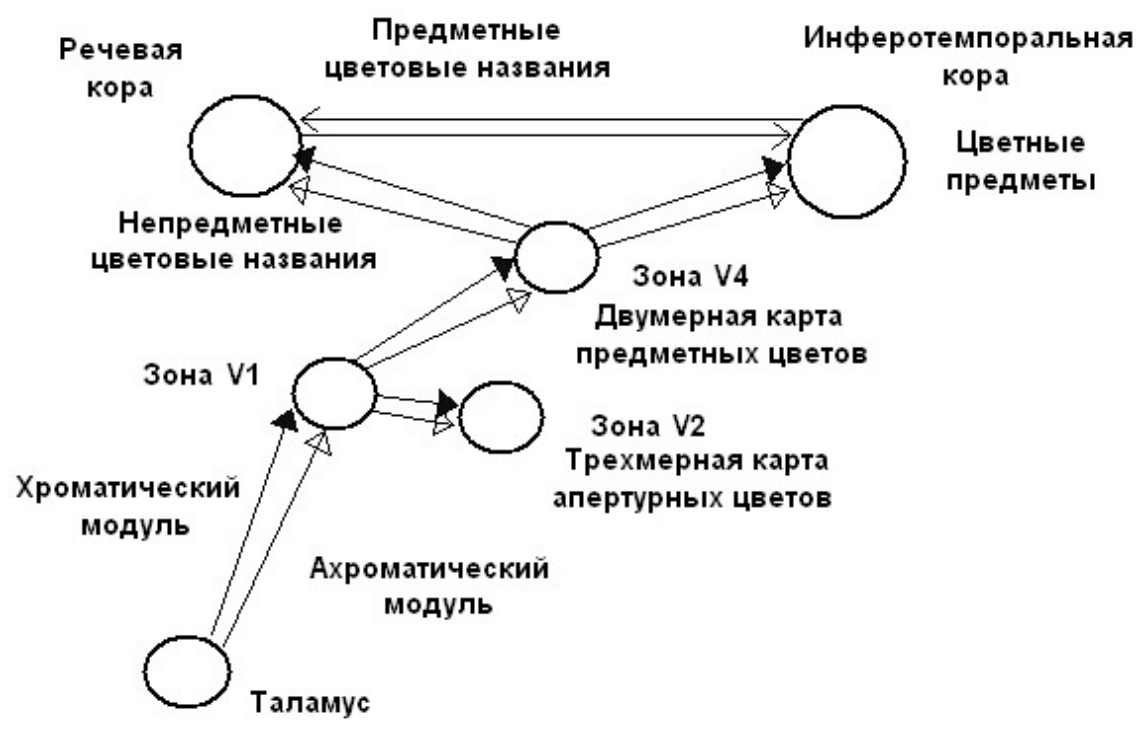

Примечание. Хроматический и ахроматический двухканальные модули параллельно и независимо передают от латерального коленчатого тела таламуса в первичную зрительную кору (зона V1) информацию о спектральном составе и интенсивности света. Из зоны V1 информация передается в зону V2, где два модуля объединяются и формируют трехмерную (тон, насыщенность, светлота) карту детекторов апертурных цветов. Эта же информация передается в зону V4, где формируется двумерная (тон и светлота) карта детекторов предметных цветов, характеризующихся константностью и фигуро-фонововой связью. Эти детекторные карты формируются уже в эмбриогенезе, а на ранних этапах онтогенеза информация от зоны V4 поступает одновременно и в инферотемпоральную кору, где она используется для формирования из различных двухканальных модулей (детектирующих цвет, текстуру, ориентацию, контур и т.д.) предметный зрительный образ (перцепта), и в речевую зону коры, где формируются базисные «непредметные» цветовые названия. Возможно, что эти связи устанавливаются до формирования конкретного речевого языка (например, в возрасте до одного года), в этом случае на роль цветовых универсалий могут претендовать названия только из набора восьми базисных цветов (темный и белый, светлый и черный, красный и зеленый, синий и желтый). По мере развития мозга устанавливаются интенсивные связи речевой коры с другими зонами коры, в частности с инферотемпоральной корой, и начинают формироваться предметные цветовые названия. Развитие связей между речевой и инферотемпоральной зонами коры расширяет набор предметных цветовых названий, и локусы «старых» предметных названий в семантическом пространстве сужаются, чтобы дать место «новому» названию. Этот эффект приближает феноменологию предметного названия к базисному непредметному названию (универсалии), так что чем более развит данный речевой язык, тем больше в нем число не только предметных, но и непредметных названий. 
обнаруживают свойства непредметных цветовых названий. Можно предположить, что за последние сто лет использования в русском языке эти названия в значительной степени отдалились от соответствующих предметов, это особенно показательно для «оранжевого», который в русском языке дополнился предметным цветовым названием «апельсиновый». Здесь права А. Вежбицкая, например, предметные цветовые названия, появляющиеся в узкоспециальной среде художников, красильщиков, полиграфистов только в профессиональных целях, постепенно распространяются среди более широких слоев населения, которое использует в речи эти названия как абстрактные, т.е. распредмечивают их. Первоначально вариабельность цветообозначения очень высока. Но по мере увеличения частоты использования она начинает снижаться, и чем больше частота использования названия, тем больше предметные названия по ассоциативной устойчивости приближаются к непредметным. Это предположение поддерживается данными по формированию искусственных цветовых названий (Izmailov, Sokolov, 1992), которые показывают, что в процессе ассоциативного обучения называть 20 спектральных цветов двадцатью искусственными трехбуквенными словами у испытуемого формируется семантическое цветовой пространство, в точности такое же, как приведено на рисунках 2 А и 3А. В этом случае можно ожидать, что список непредметных названий будет расширяться за счет абстрагирования, все более широкого и постоянного использования предметных цветовых названий в речи.

\section{Выводы}

1. Семантические пространства предметных и непредметных цветовых названий существенно отличаются от пространства цветоразличения вырожденностью такой характеристики цвета, как насыщенность. Это можно объяснить раздельным участием хроматического и ахроматического модулей цветового зрения в формирование детекторных карт цветов и цветовых названий.

2. Семантические пространства предметных и непредметных цветовых названий существенно различаются между собой по конфигурации точек-стимулов. Пространство непредметных цветовых названий имеет устойчивую конфигурацию точек-стимулов по сравнению с конфигурацией предметных цветовых названий. Изменение числа испытуемых и введение более широкого контекста стимулов приводит к незначительным вариациям первой конфигурации (непредметные названия) и к значительным вариациям второй (предметные названия). Это подтверждает позицию сторонников лингвистического разделения цветовых названий на два класса: универсальные и производные - и позволяет связать формирование непредметных цветовых названий преимущественно с психофизиологическим устройством цветового зрения, тогда как формирование предметных цветовых названий определяется речевым опытом.

3. Увеличение числа непредметных цветовых названий по мере развития языка можно объяснить расширением речевого опыта, который неизбежно приводит к увеличению 
числа предметных цветовых названий. При этом сокращается число цветовых образов, ассоциирующихся с данным предметным названием. Соответственно уменьшается разброс цветовых оценок и сужается ло- кус цветового пространства, представляющего данное название, т.е. предметное цветовое название по своим цветовым характеристикам становится идентичным непредметному, распредмеченному.

\section{Литература}

Бонгард М. Проблема узнавания. М.: Наука, 1967.

Вежбицкая А. Язык. Культура. Познание. М.: Наука, 1996.

Гете И.В. Избран.соч. по естествознанию. М.: Изд-во АН СССР, 1957.

Грегори Р. Разумный глаз. М.: Изд-во Моск. ун-та, 1972.

Джадд Д., Вышещкий Г. Цвет в науке и технике. М.: Наука, 1978.

Измайлов Ч.А. Геометрическая модель восприятия пигментных цветов // Сенсорные системы. 2010. Т. 24. № 1. С. 28-41.

Измайлов Ч.А. Многомерное шкалирование ахроматической составляющей цвета // Нормативные и дескриптивные модели принятия решений: По материалам советско-американского семинара / Под ред. Б.Ф. Ломова и др. М.: Наука, 1981. С. $98-110$.

Измайлов Ч.А. Сферическая модель цветоразличения. М.: Изд-во Моск. ун-та, 1980.

Измайлов Ч.А., Зимачев М.М., Соколов Е.Н., Черноризов А.М. Двухканальная модель ахроматического зрения лягушки // Сенсорные системы. 2006. Т. 20. № 1. C. 32-44.

Измайлов Ч.А., Павлова М.К., Ханмагомедова М. Восприятие цветных предметов // Экспериментальная психология. 2009. Т. 2. № 4. С. 5-25.

Измайлов Ч.А., Соколов Е.Н. Метрические характеристики сферической модели цветоразличения // Вестн. МГУ.
Сер. 14. Психология. 1978. № 2. C. $47-61$.

Измайлов Ч.А., Соколов Е.Н., Едренкин И.В. Интегрирование простых признаков стимула в нейронных сетях зрительной системы // Нейрокомпьютеры: Разработка и применение. 2008. № 3-4. C. 43-55.

Измайлов Ч.А., Соколов Е.Н., Черноризов А.М. Психофизиология цветового зрения. М.: Изд-во Моск. ун-та, 1989.

Кандинский В. Текст художника. М.: Ступени, 1918.

Карева Н.А. Восприятие цвета в произведениях изобразительного искусства: Дис. ... канд. филос. наук. М.: РГБ, 2005.

Келер В. Исследование интеллекта человекоподобных обезьян. М.: Изд-во Коммунистической академии, 1930.

Константинов А.И., Соколов В.А., Бъзов К.А. Основы сравнительной физиологии сенсорных систем. Л.: Изд-во ЛГУ, 1980.

Нюберг Н.Д. Опыт построения тела цветовых ощущений при заданном освещении // Вестник теор. и экспер. электротехники. 1928. Т. 1. № 6. С. 232-238; № 7. С. 248-252.

Рок И. Введение в зрительное восприятие. М.: Педагогика, 1980.

Смит К. Биология сенсорных систем. М.: Бином, 2005.

Соколов Е.Н., Измайлов Ч.А. Вызванные потенциалы в рамках сферической модели когнитивных процессов // 
Нейрокомпьютеры: разработка, применение. 2006. № 4-5.

Супин А.Я. Нейрофизиология зрения млекопитающих. М.: Наука, 1981.

Федоров Н.T. Курс общего цветоведения. М.: ОНТИ, 1935.

Фрумкина Р.М. Цвет, смысл, сходство. М.: Наука, 1984.

Шепард Р. Многомерное шкалирование и неметрические представления// Нормативные и дескриптивные модели принятия решений: По материалам советско-американского семинара / Под ред. Б.Ф. Ломова и др. М.: Наука, 1981. С. 84-97.

Шехтер М.С. Психологические проблемы узнавания. М.: Педагогика, 1967.

Яньшин П.В. Психосемантика цвета. СПб.: Речь, 2006.

Berlin B., Kay P. Basic colour terms: Their universality and evolution. Berkeley: University of California Press, 1969.

Bimler D.L., Paramei G.V., Izmailov Ch.A. Hue and saturation shifts from spatially induced blackness. // J. Opt. Soc. of Am. 2009. 26. 1. 163-172.

Grossberg $S$. Outline of a theory of brightness, color and form perception // E. Degree, J. Van Buggenhaut (eds.). Trends in mathematical psychology. Elsevier Science Publishers B.V., North-Holland, 1984. P. 59-86.

Heggelund P. A bidimensional theory of achromatic color vision // Vision Research. 1992. 32. 2107-2119.

Izmailov Ch.A., Sokolov E. N. A semantic space of color names // Psychological Science. 1992. 3. 2. 105-111.
Izmailov Ch.A., Sokolov E.N. Spherical model of color and brightness discrimination // Psychological Science. 1991. 2. 4. 249-259.

Izmailov Ch.A., Sokolov E.N. Subjective and objective scaling of large color differences // C. Kaernbach, E. Schroger, H. Muller (eds.). Psychophysics beyond sensation. Laws and invariants of human cognition. Mahwah, NJ; London: Lawrence Erlbaum Associates, 2004. P. 27-42.

Katz D. World of colour. Kegan Paul. Trench Trubner \& Co., 1935.

Kruskal J.B. Nonmetric multidimensional scaling. A numerical method // Psychometrica. 1964. 29. 2.

Martin R., Yarburton F., Morgen W. Determination of the sensitivity of the eye to differences in the sensations of colors // Med. Res. Council (Brit.) Special Rep. Ser. 188. 1933.

Shepard R.N. Attention and the metric structure of the stimulus space // J. of Mathemat. Psychol. 1964. 1. 54-87.

Shepard R.N., Carroll J.D. Parametric representations of nonlinear data structures // P.R. Krishnaiah (ed.). Multivariate Analysis. N. Y.: Academic Press, 1966. Vol. I, P. 561-592.

Sokolov E.N., Izmailov Ch.A. The conceptual reflex arc: A model of neural processing as developed for color vision // H.G. Geissler (ed.). Modern Issues of Perception. Berlin: VEB Deutscher Verlag der Wissenschaften, 1983. P. 192-216.

Wyszecki G., Stiles W.S. Color science: Concepts and methods, quantitative data and formulas. N.Y.: John Wiley \& Sons, 1982. 